\title{
Sero-Prevalence of Hepatitis D Virus Infection Among Hepatitis B Surface Antigen Positive Patients in Mashhad, Northeastern Iran
}

\author{
Sanaz Ahmadi Ghezeldasht (iD ${ }^{1}$, Mohammad Reza Hedayati-Moghaddam (iD ${ }^{1,},{ }^{*}$, Arman Mosavat (iD ${ }^{1}$ and \\ Mohammad Mehdi Akbarin ${ }^{2}$ \\ ${ }^{1}$ Blood Borne Infections Research Center, Academic Center for Education, Culture and Research, Razavi Khorasan Branch, Mashhad, Iran \\ ${ }^{2}$ Immunology Research Center, Inflammation and Inflammatory Diseases Division, Mashhad University of Medical Sciences, Mashhad, Iran \\ "Corresponding author: Blood Borne Infections Research Center, Academic Center for Education, Culture and Research, Razavi Khorasan Branch, Mashhad, Iran. Email: \\ drhedayati@acecr.ac.ir
}

Received 2019 May 18; Revised 2019 July 21; Accepted 2019 July 28.

\begin{abstract}
Background: Transmission and persistence of Hepatitis Delta Virus (HDV) depends on presence of the hepatitis B surface antigen (HBsAg) envelope proteins. The prevalence of HDV infection has not been reported previously among HBsAg-positive patients in Mashhad, Iran.

Objectives: To evaluate HDV seroprevalence among individuals with HBsAg seropositivity in Mashhad, Northeastern Iran.

Methods: This cross-sectional was performed in Central Diagnostic Lab of Academic Center for Education, Culture, and Research (ACECR), Mashhad, Iran. Based on database of the lab, $606 \mathrm{HBsAg}$ positive patients were tested for anti-HDV antibodies using the enzyme-linked immunosorbent assay (ELISA) during 2016-2017. Chi-square or Fisher's exact tests and T-test were used to analyze the data by SPSS software at a significance level of $5 \%$.

Results: Among 606 HBsAg positive patients including 335 (55.3\%) males and 271 (44.7\%) females with a mean age of $43.6 \pm 14.8$ years old, 35 cases (5.8\%) were found to be anti-HDV positive. HDV infection was more prevalent among males (6.9\%), older patients $(\mathrm{P}=0.008)$, and individuals with elevated ALT $(\mathrm{P}=0.034)$ and AST serum levels $(\mathrm{P}=0.021)$. Regarding HBV viral load, there was no significant difference between HBV/HDV co-infected and HBV mono-infected patients $(\mathrm{P}=0.07)$.

Conclusions: Prevalence of HDV infection was found to be relatively high among HBsAg-positive cases in this region. Therefore, it is suggested to assess HDV antibodies among HBsAg-positive patients, especially those with higher serum levels of transaminases.
\end{abstract}

Keywords: Hepatitis D, Hepatitis B, Prevalence, Iran

\section{Background}

Hepatitis delta virus (HDV) is a small single-stranded defective human RNA virus. This virus depends on the presence of hepatitis B surface antigen (HBsAg) envelope proteins for its transmission and persistence (1). Approximately, 15 - 20 million people around the world are co-infected with hepatitis B virus (HBV) and HDV (2). When compared to the HBV mono-infection, HBV/HDV coinfection is associated with poor clinical outcomes, rapid progression to the cirrhosis, high risk of hepatocellular carcinoma and end-stage liver disease, and the high rate of mortality related to the liver disease (3). Transition modes are the same as the HBV infection although HDV is commonly transmitted via parenteral routes, demonstrating a remarkable threat to public health (4). Currently, there is no effective therapy for HDV infection (5).

The distribution of HDV infection varies around the world with the highest prevalence rates in the Mediterranean Basin, the Middle East, central and northern Asia, sub-Saharan Africa, and South America (6). There are eight HDV genotypes scattered throughout the world. Genotype 1 is the most common genotype distributed in the Middle East, Europe, North America, and North Africa. Genotype 2 is endemic in the Far East, genotype 3 in South America, and genotypes 4 to 8 in Africa $(6,7)$. A reducing trend has been found in the epidemiology of HDV in the world including in countries with high endemicity. It could be due to the worldwide decreasing rate of HBV prevalence, $\mathrm{HBV}$ vaccination, and other preventive control measures $(8,9)$. However, migration and intravenous drug use can enhance HDV mono-infection (9).

Iran is an endemic area for hepatitis D with a prevalence of $14.4 \%$ in chronic HBV carriers, $30.47 \%$ in patients with cirrhosis, and $4.94 \%$ in inactive carriers $(10,11)$. HBV/HDV co-infection in the country differs widely from

Copyright (c) 2019, Modern Care Journal. This is an open-access article distributed under the terms of the Creative Commons Attribution-NonCommercial 4.0 International License (http://creativecommons.org/licenses/by-nc/4.0/) which permits copy and redistribute the material just in noncommercial usages, provided the original work is properly cited. 
zero in Sari, northern Iran, to $17.3 \%$ in Hamadan, western Iran $(12,13)$. Mashhad located in the northeast of Iran is a large city attracting many pilgrims from different parts of Iran and other countries. There are limited data about HDV infection frequency in this area (14).

\section{Objectives}

This study aimed to evaluate the prevalence of HDV infection and its association with HBV serological markers and liver transaminases among HBsAg-positive patients in Mashhad, northeastern Iran.

\section{Methods}

\subsection{Study Population}

This cross-sectional study was carried out on individuals admitted to the Central Diagnostic Lab of Academic Center for Education, Culture, and Research (ACECR), Razavi Khorasan Branch, Mashhad, Iran, from March 2017 to March 2018.

Based on the electronic database of the laboratory, anti-HDV antibody testing had been carried out for 606 HBsAg-seropositive individuals who referred to the laboratory during this period. The Research and Technology Deputy of ACECR, Razavi Khorasan Branch, approved the study for methodological and ethical issues (No.96.48.1745).

\subsection{Laboratory Studies}

The tests for serum HBsAg, hepatitis B e antigen (HBeAg), and antibody against HBeAg (anti-HBe) had been performed using commercial enzyme-linked immunosorbent assay (ELISA) kits (General Biologicals Corporation, Taiwan). Serum anti-HDV antibody tests had been also carried out via ELISA kits (DIA PRO Diagnostic Bioprobes, Srl., Italy). The serum concentration of alanine transaminase (ALT) and aspartate transaminase (AST) also had been assessed (Auto analyzer, Liasys, Germany). HBV viral DNA had been extracted from serum samples by the QIAamp DNA Blood Mini Kit (QIAGEN) and quantitative analysis of HBV DNA PCR had been performed using COBAS TaqMan HBV assay (Roche Diagnostics) according to the manufacturer's instruction.

\subsection{Statistical Analysis}

Statistical analysis was performed using SPSS version 19 software. Continuous variables are displayed as means $\pm \mathrm{SD}$ and categorical variables as frequencies and percentages. The chi-square test or Fisher's exact test were used to compare statistical differences in the categorical variables between the groups. Independent sample $t$-test was used to compare the means of HBV viral load between the groups. The statistical significance level was considered at $5 \%$.

\section{Results}

Among 606 HBsAg-positive individuals tested for the anti-HDV antibodies, 335 patients were male (55.3\%) and 271 were female (44.7\%). Participants' age ranged from 12 to 96 years with a mean of $43.6 \pm 14.8$ years. Serum samples of 35 subjects (5.8\%) were positive for anti-HDV antibodies. As Table 1 shows, HDV infection was more prevalent among older subjects $(\mathrm{P}=0.008)$. The frequency of elevated AST and ALT serum levels ( $>40 \mathrm{mg} / \mathrm{dL}$ ) were remarkably higher in HDV-positive cases than in HDV-negative cases $(\mathrm{P}=0.021$ and $\mathrm{P}=0.034$, respectively). There were no significant differences between two groups regarding patients' sex, the rates of HBeAg and Anti-HBe seropositivity and HBV viral load.

\section{Discussion}

Eastern Mediterranean basin and Middle East countries are endemic areas for HDV infection. Iran, as one of the countries located in the Middle East, shows a high prevalence of HDV infection, which differs from region to region (15). Therefore, estimating the prevalence of this viral infection in an area with a high prevalence seems necessary. This study demonstrated the HDV seropositivity rate of 5.8\% among HBsAg positive patients who referred to ACECR lab in Mashhad.

Previous seroepidemiological studies showed different HDV seropositivity results among Iranian patients with no consistent pattern. The rate of HDV was reported to be zero in Mazandaran, 1.7\% in Kermanshah, 2\% in Qom, 2.9\% in Isfahan, 5.8\% in Golestan, 7.7\% in Tehran, 11.5\% in Khuzestan, $17 \%$ in Sistan and Baluchistan, and $17.3 \%$ in Hamadan provinces $(9,12,13,16-21)$. Amini et al. (11) in a systematic review of epidemiological studies reported the overall HDV seropositivity rate of $6.61 \%$ among Iranian patients with chronic HBV infection. Variations in HDV prevalence in different geographical areas in the country demonstrate that risk factors for HDV infection differ between the regions (16). Furthermore, discrepancies between different areas of the country in the severity of the disease among studied populations might be another reason for different frequencies of the infection. Amini et al. review (11) estimated that the HDV prevalence is considerably higher in cirrhotic patients (30.47\%) than in those with chronic hepatitis (14.4\%) and inactive carriers (4.94\%). The findings of 


\begin{tabular}{|c|c|c|c|}
\hline Variables & HDV Positive & HDV Negative & P Value \\
\hline Age, y; mean \pm SD & $59.03 \pm 16.39$ & $43.23 \pm 14.67$ & 0.008 \\
\hline Gender & & & 0.201 \\
\hline Male & $23 / 35(65.7)$ & $311 / 570(54.6)$ & \\
\hline Female & $12 / 35(34.3)$ & $259 / 570(45.4)$ & \\
\hline Elevated serum SGOT & $12 / 24(50.0)$ & $104 / 373(27.9)$ & 0.021 \\
\hline Elevated serum SGPT & $12 / 24(50.0)$ & $111 / 377(29.4)$ & 0.034 \\
\hline HBeAg seropositivity & $0 / 18(0)$ & $27 / 337(8.0)$ & 0.212 \\
\hline Anti-HBe seropositivity & $9 / 11(81.8)$ & $219 / 271(80.8)$ & 0.198 \\
\hline HBV viral load, log10, mean \pm SD & $2.055 \pm 2.542$ & $3.324 \pm 3.048$ & 0.071 \\
\hline
\end{tabular}

${ }^{\mathrm{a}}$ Values are expressed as No. (\%) unless otherwise indicated.

the present study showed that the HDV infection prevalence is lower in Iran than in its neighboring countries. The HDV infection rate was reported to be as high as $14.66 \%$ among $1890 \mathrm{HBV}$ patients from east and northwest of Pakistan (22). Likewise, the prevalence rates of the infection in Turkey (9.6\%) and Iraq (6.6\%) were higher than the prevalence reported in the present study $(23,24)$. Furthermore, an earlier study demonstrated a significantly higher HDV seroprevalence (26.66\%) among Afghans who immigrated to Iran than among Iranian patients (1.85\%) (25).

The current study in agreement with Tahaei et al. (19) and Sayad et al. (9) studies showed no significant relationship between gender and HDV seropositivity. However, some previous investigations demonstrated a greater seroprevalence for hepatitis $\mathrm{D}$ in men than in women due to the higher prevalence of risk behaviors among men $(13,21)$. On the other hand, in the present study, HDV seropositivity was more prevalent among older patients, which could be attributed to the reduced immunity, particularly compromised immune system in the elderly (26). Furthermore, in line with the results of Binh et al. (27) and Tahaei et al. (19) studies, the present study demonstrated higher levels of ALT and AST in HDV-seropositive patients probably due to that HDV infection intensifies liver inflammation (28).

Additionally, similar to the results of previous studies $(3,27)$, the present study showed higher levels of HBV DNA in HBV mono-infected patients than in co-infected patients; however, the difference was not statistically significant. Although HBV supplies envelope proteins and is crucial for HDV viremia and infectivity, HDV hinders HBV replication at a definite point of the coinfection due to the interference mechanisms that remain to be elucidated (29). In this study, there was no correlation between anti-HDV positivity and HBeAg/anti-HBe seroreactivity. Similarly, in a cross-sectional study by Ziaee and Azarkar (30) on chronic hepatitis B patients, no association was found between positive anti-HDV serology and positive HBeAg serology.

\subsection{Conclusions}

In summary, hepatitis delta prevalence in Mashhad, northeast of Iran, was moderately high. HDV seropositivity was more prevalent among older people and those with higher ALT and AST levels. Considering the high prevalence of HDV in this area, screening of HDV antibodies is proposed in HBV patients, particularly those with elevated levels of ALT and AST.

\section{Footnotes}

Authors' Contribution: Mohammad Reza HedayatiMoghaddam designed the study. Arman Mosavat, Sanaz Ahmadi Ghezeldasht, and Mohammad Mehdi Akbarin performed the assays and contributed to data interpretation. All authors wrote and reviewed the manuscript.

Conflict of Interests: It is not declared by the authors.

Ethical Approval: The study was approved by the Research and Technology Deputy of Academic Center for Education, Culture, and Research (ACECR), Razavi Khorasan Branch, Mashhad, Iran (IR.ACECR.JDM.REC.1397.3).

Funding/Support: This study was financially supported by the ACECR.

\section{References}

1. Patel EU, Thio CL, Boon D, Thomas DL, Tobian AAR. Prevalence of hepatitis B and hepatitis D virus infections in the United States, 2011-2016. Clin Infect Dis. 2019. doi: 10.1093/cid/ciz001. [PubMed: 30605508].

2. Butler EK, Rodgers MA, Coller KE, Barnaby D, Krilich E, Olivo A, et al. High prevalence of hepatitis delta virus in Cameroon. Sci Rep. 2018;8(1):11617. doi: 10.1038/s41598-018-30078-5. [PubMed: 30072752]. [PubMed Central: PMC6072717]. 
3. Coghill S, McNamara J, Woods M, Hajkowicz K. Epidemiology and clinical outcomes of hepatitis delta (D) virus infection in Queensland, Australia. Int J Infect Dis. 2018;74:123-7. doi: 10.1016/j.ijid.2018.07.005. [PubMed: 30003953].

4. Villar LM, Milagres FAP, Lampe E, Cruz HM, Scalioni LP, Magalhaes M, et al. Determination of hepatitis $\mathrm{B}, \mathrm{C}$ and $\mathrm{D}$ prevalence among urban and Amerindian populations from the Eastern Brazilian Amazon: A cross sectional study. BMC Infect Dis. 2018;18(1):411. doi: 10.1186/s12879018-3279-2. [PubMed: 30126364]. [PubMed Central: PMC6102873].

5. Krause A, Haberkorn U, Mier W. Strategies for the treatment of HBV/HDV. Eur J Pharmacol. 2018;833:379-91. doi: 10.1016/j.ejphar.2018.06.030. [PubMed: 29935174].

6. Daw MA, Daw AM, Sifennasr NEM, Draha AM, Daw AM, Daw AM, et al. The epidemiology of hepatitis D Virus in North Africa: A systematic review and meta-analysis. ScientificWorldJournal. 2018;2018:9312650. doi: 10.1155/2018/9312650. [PubMed: 30356409]. [PubMed Central: PMC6178169].

7. Gourari S, Brichler S, Le Gal F, Abdou-Chekaraou M, Beloufa MA, Khelifa R, et al. Hepatitis B virus and hepatitis delta virus subtypes circulating in Algeria and seroprevalence of HDV infection. J Med Virol. 2019;91(1):72-80. doi: 10.1002/jmv.25301. [PubMed:30168584].

8. Luma HN, Eloumou S, Okalla C, Donfack-Sontsa O, Koumitana R, Malongue A, et al. Prevalence and characteristics of hepatitis delta virus infection in a tertiary hospital setting in Cameroon.J Clin Exp Hepatol. 2017;7(4):334-9. doi: 10.1016/j.jceh.2017.05.010. [PubMed: 29234199]. [PubMed Central: PMC5715454].

9. Sayad B, Naderi Y, Alavian SM, Najafi F, Janbakhsh A, Mansouri F, et al. Hepatitis D virus infection in Kermanshah, west of Iran: Seroprevalence and viremic infections. Gastroenterol Hepatol Bed Bench. 2018;11(2):145-52. [PubMed: 29910856]. [PubMed Central: PMC5990919].

10. Ghamari S, Alavian SM, Rizzetto M, Olivero A, Smedile A, Khedive A, et al. Prevalence of hepatitis delta virus (HDV) infection in chronic hepatitis B patients with unusual clinical pictures. Hepat Mon. 2013;13(8). e6731. doi: 10.5812/hepatmon.6731. [PubMed: 24098308]. [PubMed Central: PMC3787685].

11. Amini N, Alavian SM, Kabir A, Saiedi Hosseini SY, Aalaei Andabili SH. Clinical features and seroepidemiology of anti-HDV antibody in patients with chronic hepatitis B virus infection in Iran: A meta-analysis. Hepat Mon. 2011;1(12):960-7. doi: 10.5812/kowsar.1735143X.805. [PubMed: 22368679]. [PubMed Central: PMC3282028].

12. Taghvaei T, Khanlarpoor M, Mahdavi MR, Tirgar Fakheri H, Maleki E, Khalilian AR. [Prevalence of positive hepatitis delta virus in patients with positive hepatitis B surface antigen and its correlative factors in Sari]. J Mazandaran Univ Med Sci. 2008;18(67):102-6. Persian.

13. Mohammad Alizadeh AH, Ranjbar M, Tehrani AS, Keramat F, Mamani M, Rezazadeh M, et al. Seroprevalence of hepatitis D virus and its risk factors in the west of Iran.J Microbiol Immunol Infect. 2010;43(6):51923. doi: 10.1016/S1684-1182(10)60080-1. [PubMed: 21195980].

14. Sadeghian H, Varasteh N, Esmaeelzadeh A, Nomani H, Alimardani M, Davoodnejad M, et al. Distribution of hepatitis delta virus genotypes in Mashhad, northeast Iran. Jundishapur J Microbiol. 2015;8(2). e14908. doi:10.5812/jjm.14908. [PubMed: 25793092]. [PubMed Central: PMC4353030].

15. Amini N, Alavian SM, Kabir A, Aalaei-Andabili SH, Saiedi Hosseini SY, Rizzetto M. Prevalence of hepatitis d in the eastern mediterranean region: Systematic review and meta analysis. Hepat Mon. 2013;13(1). e8210. doi: 10.5812/hepatmon.8210. [PubMed: 23554822]. [PubMed Central: PMC3609404]

16. Ghadir MR, Belbasi M, Heidari A, Sarkeshikian SS, Kabiri A, Ghanooni $\mathrm{AH}$, et al. Prevalence of hepatitis d virus infection among hepatitis B virus infected patients in qom province, center of Iran. Hepat Mon.
2012;12(3):205-8. doi: 10.5812/hepatmon.847. [PubMed: 22550529] [PubMed Central: PMC3339421].

17. Ataei B, Yazdani MR, Kalantari H, Yaran M, Nokhodian Z, Javad AA, et al. Hepatitis D virus infection in Isfahan, central Iran: Prevalence and risk factors among chronic HBV infection cases. Hepat Mon. 2011;11(4):269-72. [PubMed: 22706272]. [PubMed Central: PMC3206699].

18. Roshandel G, Semnani S, Abdolahi N, Besharat S, Keshtkar AA Joshaqani $\mathrm{H}$, et al. Prevalence of hepatitis D virus infection in hepatitis B surface antigen-positive subjects in Golestan province, northeast Iran. J Microbiol Immunol Infect. 2008;41(3):227-30. [PubMed: 18629418].

19. Tahaei SM, Mohebbi SR, Azimzadeh P, Behelgardi A, Sanati A, Mohammadi $P$, et al. Prevalence of hepatitis D virus in hepatitis B virus infected patients referred to Taleghani hospital, Tehran, Iran. Gastroenterol Hepatol Bed Bench. 2014;7(3):144-50. [PubMed: 25120894] [PubMed Central: PMC4129564].

20. Eskandar H, SeyedJalal H, Fariba J. Seroprevalence of delta hepatitis in patients with chronic hepatitis B and its clinical impact in Khuzestan province, southwest Iran. Hepat Mon. 2009;9(4):287-92.

21. Bakhshipour A, Mashhadi M, Mohammadi M, Nezam SK. Seroprevalence and risk factors of hepatitis delta virus in chronic hepatitis $\mathrm{B}$ virus infection in Zahedan. Acta Med Iran. 2013;51(4):260-4. [PubMed: 23690107]

22. Aftab M, Amin I, Idrees M, Ali A, Rafique S, Naz S. Molecular epidemiology of hepatitis delta and hepatitis B viruses circulating in two major provinces (East and North-West) of Pakistan. Infect Genet Evol. 2018;64:65-9. doi:10.1016/j.meegid.2018.06.013. [PubMed: 29906637].

23. Sahin A, Gurocak S, Tunc N, Demirel U, Poyrazoglu OK, Akbulut H, et al. Anti-HDV seroprevalance among patients with previous HBV infection. North Clin Istanb. 2018;5(2):132-8. doi: 10.14744/nci.2018.01328. [PubMed: 30374479]. [PubMed Central: PMC6191552].

24. Hussein NR, Rasheed ZA, Taha AA, Shaikhow SK. The prevalence of hepatitis D Virus infection amongst patients with Chronic active hepatitis B Virus infection in Duhok Governorate. Int J Pure Appl Sci Technol. 2015;28(1):1-7.

25. Keshvari M, Alavian SM, Aghaee B, Behnava B, Mahdavi M, Fesharaki MG, et al. Seroepidemiology and clinical features of hepatitis delta among HBsAg carriers: A study from Hepatitis Clinic of Iranian Blood Transfusion Organization. Transfus Med. 2014;24(6):411-7. doi: 10.1111/tme.12163. [PubMed: 25523297].

26. Montecino-Rodriguez E, Berent-Maoz B, Dorshkind K. Causes, consequences, and reversal of immune system aging. J Clin Invest 2013;123(3):958-65. doi: 10.1172/JCI64096. [PubMed: 23454758]. [PubMed Central: PMC3582124].

27. Binh MT, Hoan NX, Van Tong H, Giang DP, Sy BT, Toan NL, et al HDV infection rates in northern Vietnam. Sci Rep. 2018;8(1):8047. doi: 10.1038/s41598-018-26446-w. [PubMed: 29795302]. [PubMed Central: PMC5966401].

28. Honer $\mathrm{Zu}$ Siederdissen C, Cornberg M. Management of HBV and HBV/HDV-associated liver cirrhosis. Visc Med. 2016;32(2):86-94. doi: 10.1159/000445518. [PubMed: 27413725]. [PubMed Central: PMC4926882].

29. Shirvani-Dastgerdi E, Tacke F. Molecular interactions between hepatitis B virus and delta virus. World J Virol. 2015;4(2):36-41. doi: 10.5501/wjv.v4.i2.36. [PubMed: 25964870]. [PubMed Central: PMC4419120].

30. Ziaee M, Azarkar G. Prevalence of hepatitis d virus infection among patients with chronic hepatitis B attending birjand hepatitis clinic (East of iran) in 2012. Hepatmon. 2013;13(8). e11168. doi: 10.5812/hepatmon.11168. [PubMed: 24171009]. [PubMed Central: PMC3800676]. 